\title{
EVALUACIÓN AMBIENTAL DE URBANIZACIONES TURÍSTICAS. Paisaje Protegido Laguna de Rocha y su área adyacente (sector oeste)
}

\author{
autor: Mg. Arq. Javier Prieto \\ directora tesis: Dra. Lorena Rodríguez Gallego \\ tesis: Maestría en Ciencias Ambientales I Facultad de Ciencias I UdelaR \\ email: javierprietovillella@gmail.com
}

\section{RESUMEN}

En la costa atlántica uruguaya el turismo internacional es motor de crecimiento económico, pero al mismo tiempo impone lógicas externas modificando sociedad y territorio con nuevos modelos urbano-turísticos. A pesar que el ordenamiento territorial refiere al paradigma contemporáneo de planificación estratégica, participativa y sustentable, la realidad no siempre lo demuestra.

Este trabajo identifica un caso caracterizado por tensiones extremas entre planificación del desarrollo urbano-turístico y conservación de biodiversidad en áreas protegidas.

El objetivo fue desarrollar una metodología capaz de identificar lugares preferenciales de implantación y modelos urbano-turísticos, para evaluar su aptitud ambiental pretendiendo minimizar impactos en el paisaje y sistema natural, promoviendo el desarrollo social y económico.

Se concretó adaptando procedimientos de SIG, evaluación ambiental y teoría de la decisión, posibilita integrar especialistas, actores, variables del territorio, dimensiones del desarrollo y reglamentaciones. Por presentar datos y procesos explícitos, viabiliza acuerdos y decisiones de consenso, sustituyendo elecciones intuitivas por justificadas.

Palabras clave: Sustentabilidad ambiental, Desarrollo urbano-turístico, Conservación de biodiversidad, Análisis de aptitud

\section{ABSTRACT}

In the Uruguayan Atlantic coast, international tourism is the engine of economic growth, but at the same time it imposes external logics that modify society and territory with new urban-tourist models. Nowadays, planning refers to the contemporary paradigm of paradigm of strategic planning, participation and sustainability, but this is not always done in this way.

This work identifies a case characterized by extreme tensions between urban-tourism development planning and the conservation of biodiversity in protected areas.

The objective was to develop a methodology able of identifying preferential places of implementation and urban-tourist models. In this way, assess their environmental suitability; minimize impacts on the landscape and the natural system and promoting social and economic development.

It was finalized by adapting GIS procedures, environmental assessment and decision theory, in order to integrate specialists, actors, territorial variables, development and regulations. By presetting explicit data and processes, it allows consensus agreements and decisions, replacing intuitive options with justifications.

Keywords: Environmental sustainability, Urban-tourist development, Conservation of biodiversity, suitability analysis 


\section{INTRODUCCIÓN}

El trabajo de tesis aborda un complejo conflicto entre desarrollo urbano-turístico (UT) y conservación de biodiversidad pretendiendo comprender e incidir positivamente en la transformación en curso del territorio. El sector de la costa Atlántica, limítrofe entre Maldonado y Rocha ha sido galardonado a nivel nacional e internacional por valores naturales y culturales excepcionales. Se encuentran las Áreas Protegidas Laguna Garzón (APLG) y Laguna de Rocha (APLR) del Sistema Nacional de Áreas Protegidas (SNAP) del Ministerio de Vivienda, Ordenamiento Territorial y Medio Ambiente (MVOTMA). A pesar de los riesgos planteados por diversos especialistas, en el sector ubicado entre éstas, resulta inminente la ocupación con UT privadas, cerradas y gran superficie continuando la tendencia proveniente de la aglomeración urbana con centro en Punta del Este. La Intendencia de Rocha (IDR) mediante el Plan Local de Ordenamiento Territorial Lagunas Costeras (PLOTLC IDR, 2010), incorpora 33.600 habitantes en 13.000 hás aproximadamente (gráfico 1).

El plan no se ha materializado en el territorio, pero debido al creciente y sostenido aumento del turismo, el nuevo puente en Laguna Garzón, así como los cambios de la política económica Argentina (principal grupo de turistas e inversores), podría desencadenarse explosivamente su desarrollo con resultados inciertos.

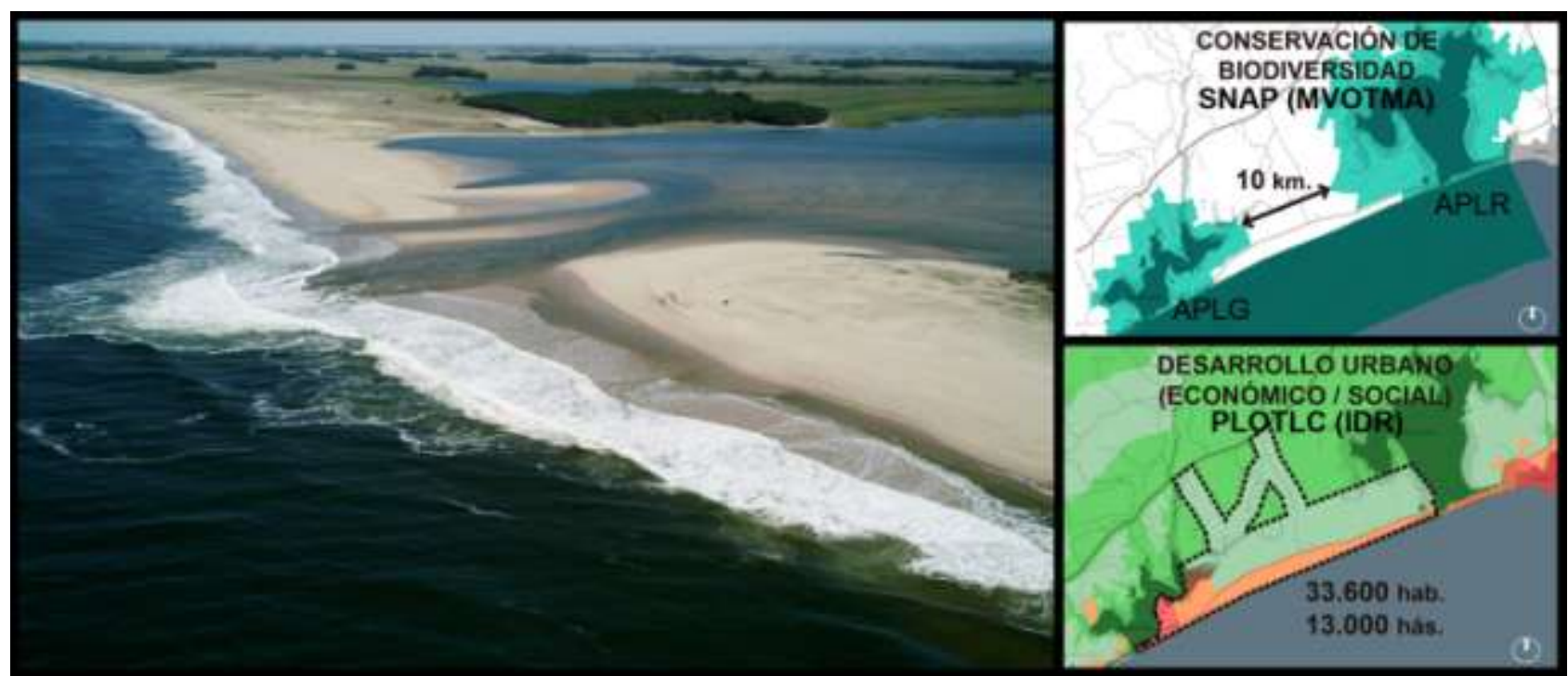

Gráfico 1: Izquierda, Imagen del área de estudio, desembocadura de la Laguna de Rocha (foto IdD-Fadu, por Ruik, A.). Derecha, mapeo de Áreas Protegidas Laguna Garzón y Laguna de Rocha (SNAP), así como zonas a urbanizar del PLOTLC (SIG del MVOTMA).

Según la OMT (2016), el turismo se ha convertido en uno de los principales actores del comercio internacional, sustancial para países en desarrollo, donde el ingreso de divisas extranjeras dinamiza el mercado activando el desarrollo local y la distribución de riquezas. Pero dentro del marco teórico analizado, con una visión más crítica, Hernández (2009), Benseny (2006), Brenes (2006), Svampa (2001), Fernández (2000), Bervejillo (1996) lo identifican como uno de los principales agentes transformadores del territorio asociado al proceso de globalización. Alertan que la relación entre lo global y lo local es trascendental, ya que los procesos transnacionales imponen nuevas lógicas globales sobre regiones y localidades. Advierten que los beneficios económicos traen profundos impactos negativos, principalmente en el sistema social, el natural y el paisaje, con la imposición de nuevas formas de desarrollo territorial. Se incorporan nuevos modelos de UT, apoyados en nuevos valores de carácter internacional característicos de la globalización, rearticulando las relaciones existentes entre la sociedad y el territorio, construyendo una nueva identidad, un nuevo territorio. Así mismo, identifican a la planificación territorial como factor clave para maximizar beneficios y disminuir pérdidas, posibilitando transformar amenazas en oportunidades de desarrollo social y conservación de biodiversidad, redundando en salud y bienestar de las comunidades locales.

Améndola (2000) afirma que en el siglo XXI ha habido un cambio sustancial con respecto a la ciudad del siglo XX. La nueva ciudad, modifica la ciudad física a partir de la mutación de imaginario, sueños, deseos y miedos, incorpora demandas como belleza, seguridad, significación y variedad que no se encontraron en el proyecto moderno. En este nuevo contexto, los principales factores que actúan sobre la forma de la ciudad y 
su organización son: mercado inmobiliario, exigencias de valorización del capital y consumo de masas. Se refuerza la lógica de competencia y especulación en base a distinción social, identidades prefabricadas, moda y gustos (Améndola, 2000). Por otro lado, Svampa (2001) que analizó el proceso de privatización en nuestro continente y especialmente en Argentina, plantea que los nuevos modelos de urbanizaciones definidos por las nuevas tendencias son la manifestación material de su sistema socioeconómico. Afirma que en Latinoamérica "El modelo urbano que se desarrolló es de ciudad abierta basado en el contacto entre grupos, pero la fractura social se evidencia en guetos de pobreza (favelas, villa miseria, cantegriles). En la actualidad el proceso de la globalización acentuó la fractura llevando el modelo de ciudad abierta, hacia el régimen de ciudad cerrada, conviviendo ambas en el territorio" (Svampa, 2001:14-15). Según Graciela Benseny (2006) "El turismo en el espacio, implica un elevado consumo del suelo, que asociado a las prácticas recreativas, genera diversos modelos de implantación y transformación de estructuras territoriales, sociales y económicas. El acondicionamiento turístico requiere la instalación de un conjunto de facilidades capaces de generar y mantener la demanda turística... El equilibrio entre el turismo y el ambiente se basa en la capacidad de carga de los recursos, es decir el número de visitantes que las playas, lagunas o reservas ecológicas pueden soportar en un determinado momento sin producir daños en el ecosistema" (Benseny, 2006:103). De acuerdo a esta autora se puede generar impactos medioambientales negativos o positivos, obedeciendo a su planificación y control de su desarrollo. La zona impactada depende del tipo y escala del desarrollo turístico, así como también de las características medioambientales del lugar.

En ordenamiento territorial y protección ambiental se han incorporado al marco jurídico de los países de América del Sur el concepto de desarrollo sustentable (DS), mediante la planificación estratégica, descentralizada y participativa, pero su aplicación reciente ha tenido resultados dispares (Panizza et al., 2014). Varios autores analizaron críticamente este fenómeno, Fernández (2000) afirma que las principales dificultades son estructurales y refieren a la crisis del Estado, con un rol más de gestor que planificador. Otra crítica, refiere al papel de los sectores marginales y las dificultades para la participación, según Arocena (1997) "las políticas tendientes a aumentar las autonomías locales podrían producir un efecto perverso... Si los intereses que dominan el sistema son transnacionales, mal puede una débil sociedad local defender su interés, será siempre víctima del desarrollo reproductivo del sistema" (Arocena, 1997:11). Así mismo, la complejidad y falta de información en temáticas ambientales, la desconexión entre comunidad y técnicos, son una barrera de participación genuina. Otra dificultad, que constatan Panizza et al. (2014), Allen (1998), Fernández (2000), es la falta de rigor operativo del concepto de DS, con interpretaciones divergentes y muchas veces contradictorias.

\section{2: ANTECEDENTES}

Analizando el proceso de transformación territorial en curso de Maldonado a Rocha, en conjunto con el marco normativo de ordenamiento territorial y protección ambiental el caso se estructuró en tres escalas territoriales (gráfico 2).

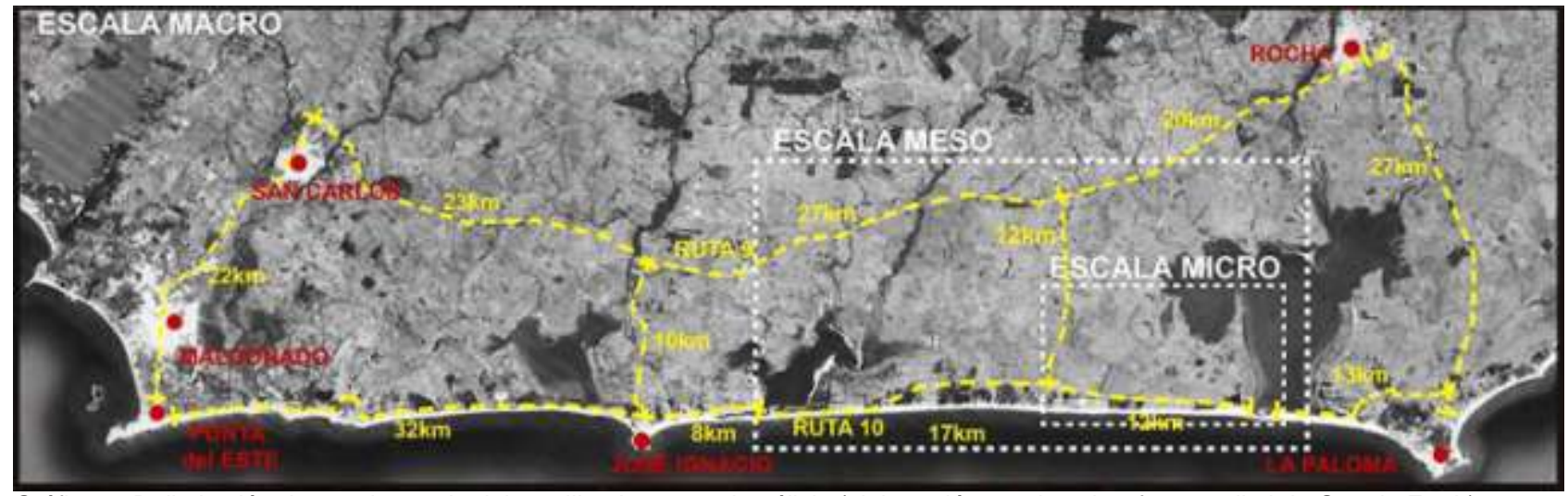

Gráfico 2: Delimitación de escalas territoriales utilizadas para el análisis (elaboración propia sobre foto satelital de Google Earth).

El proceso de conformación balnearia de la costa este Uruguaya comienza con el turismo de sol y playa (SXX), mediante propuestas relacionadas con un hotel como atractor principal. Empresarios y propietarios de la tierra creaban un consorcio para fraccionamiento y venta. Mediante procedimientos de venta interesantes con mucha publicidad, se capta una clase media muy fuerte, con tiempo libre para usar los fines de semana. El modelo referencia en esta primer etapa es el balneario de tipo europeo, ubicándose en las costas de Canelones, Maldonado y Rocha. En las últimas décadas, el turismo litoral presenta un crecimiento 
sostenido incorporando nuevas modalidades para un nuevo público, la ruralidad en modelos de chacras marítimas y barrios privados, así como enclaves de urbanidad en el paisaje natural con torres en altura (Articardi, 2014). En el gráfico 3 se sintetizan las principales características de estos modelos.

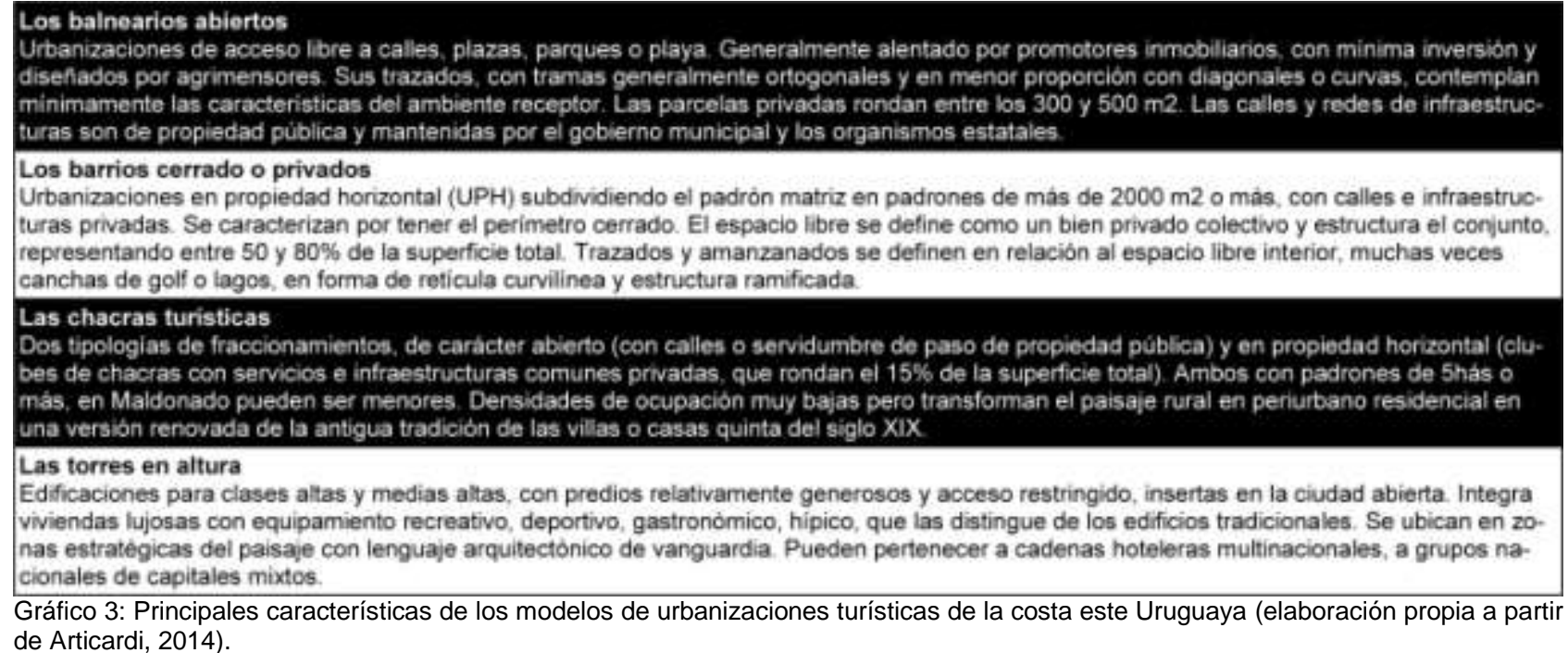
de Articardi, 2014).

Actualmente, el proceso que se desarrolla en Maldonado, está estrechamente vinculado al crecimiento del turismo y tiende a ser replicado en Rocha. El crecimiento económico derivado de esta actividad ha mejorado las condiciones de vida de la población local, disminuyendo el desempleo y la pobreza. Sin embargo, Leicht, et al (2013) explican que la migración interna del país que llega buscando fuentes laborales, se ubica en zonas periféricas ambientalmente frágiles en condiciones insalubres (bajos salarios, empleos zafrales, extenso horario y alejados de sus residencias), mientras que la migración externa, ocupa suelos productivos (entre balnearios costeros existentes y zonas contiguas) con nuevas urbanizaciones privadas, de grandes superficies y cerradas, apropiando sitios privilegiados, modificando el paisaje, afectando casi todo el frente costero de Maldonado. Destacan como consecuencias más preocupantes: crecimiento explosivo de población y mancha urbana, fragmentación socio-espacial (guetos de ricos y pobres), distribución desigual de riquezas, especulación inmobiliaria, contaminación de cuerpos de agua, entre otras (Leicht, et al., 2013). Para explicar en números este proceso se presenta el gráfico 4 que sintetiza los principales indicadores socio-económicos de Maldonado y Rocha extraídos del diagnóstico del Plan Estratégico de Desarrollo de la Región Este (ERC, 2012) realizado por las Intendencias de Maldonado, Rocha, Lavalleja y Treinta y Tres.

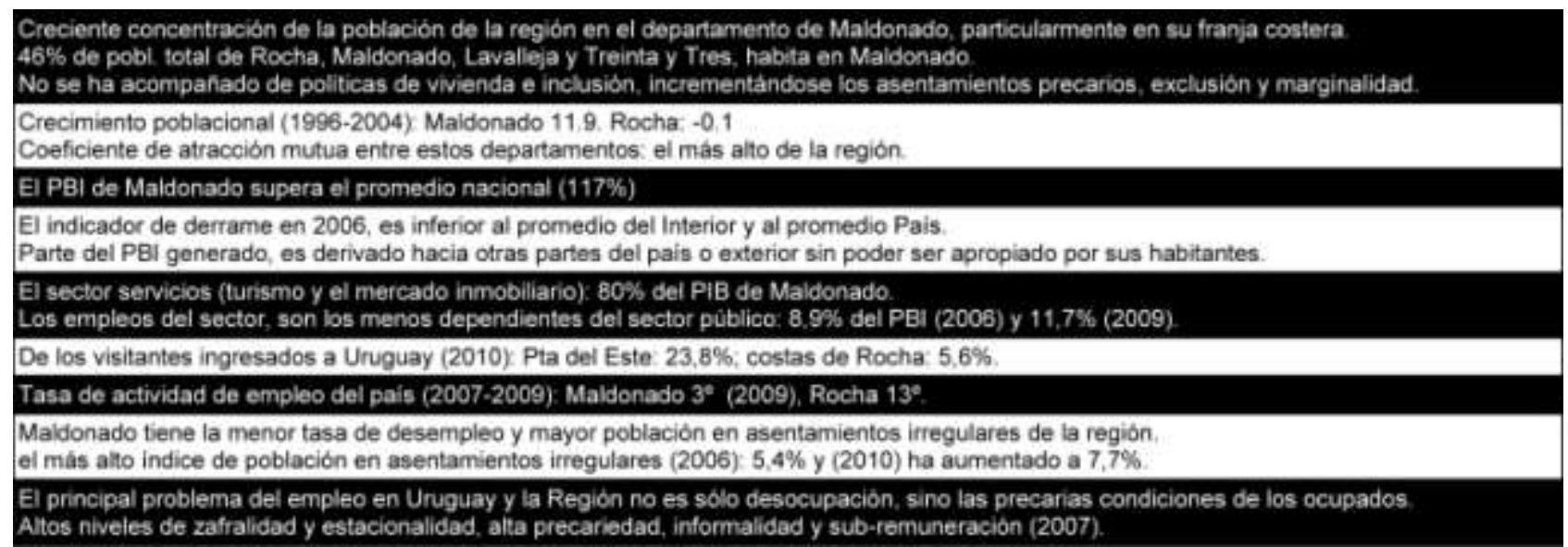

Gráfico 4: Maldonado y Rocha en cifras, síntesis del diagnóstico realizado para el Plan estratégico de desarrollo de la región Este (elaboración propia a partir de ERC, 2012)

Los siguientes apuntes del Instituto de Teoría y Urbanismo (ITU, Farq, UdelaR, asesor de la Intendencia de Maldonado, para la definición e implementación gradual de un sistema de planificación estratégica para el ordenamiento territorial del Departamento) brindan el panorama del escenario territorial esperado. De acuerdo a los análisis efectuados, "la aglomeración central del departamento, Maldonado-Punta del EsteSan Carlos con los balnearios y poblados costeros, en pocos años, será la segunda zona metropolitana más grande del país. Ya en el 2004 alcanzaba a 111.000 habitantes permanentes, y para el año 2025 se estima 
que la población permanente pasaría a 156.000 habitantes, que sumada a la población visitante en el momento pico de la alta temporada (enero - febrero), el área metropolitana contaría con una población estimada entre 400 mil y medio millón de habitantes" (Acuña et al., 2011:48).

Los antecedentes normativos utilizados en el trabajo, refieren a las principales herramientas de ordenamiento territorial y protección ambiental. En el país el encargado de ejercer el ordenamiento del territorio y la protección ambiental es el Estado, que en las últimas décadas incorporó coordinadamente al marco jurídico los conceptos de: desarrollo sostenible, protección ambiental, planificación estratégica, participación ciudadana y descentralización. Si bien el gobierno central (MVOTMA) tiene la competencia de la planificación en el ámbito nacional, en lo departamental se le atribuye a los Gobiernos Departamentales, pero los instrumentos que elabore deben contar con su aprobación. Apoyado en textos de analistas especializados, Cousillas (2016), Nario, (2015), Sciandro (2013), Neme et al. (en Rodríguez-Gallego et al., 2012 $2^{\text {a }}$ ) se estudian comparativamente, entre otros la Ley de Ordenamiento Territorial y Desarrollo Sustentable (LOTDS 18.308/08, Regl. Dec. 221/09), Ley de descentralización política y participación ciudadana (Ley № 18.567/09, modificada 19.272/14), Ley de creación del SNAP (17.234/00 modificada 7.930/05, Regl. Dec. № 52/005), Ley general de protección del ambiente LGA 17.283/2000, Ley de evaluación de impacto ambiental (EIA 16.466/94, Dec. Regl. 435/94 y 349/05). Así mismo a escala menor, se analizan detalladamente los lineamientos del PLOTLC (IDR, 2010) y el Plan de Manejo del PPLR (PPLR. Rodríguez-Gallego et al, 2012a).

\section{1: EL PLAN LOCAL DE ORDENAMIENTO TERRITORIAL LAGUNAS COSTERAS (IDR, 2010)}

El documento se inicia con el modelo de desarrollo deseado: "Se propone un modelo de desarrollo y ocupación del territorio, que signifique un beneficio para el país, en general y para el Departamento en particular, poniendo en valor sus recursos territoriales. Se pretende con ello, la promoción de emprendimientos que utilicen mano de obra altamente calificada en todas las ramas, que agregue valores a los bienes y servicios producidos en el Departamento, propiciando la capacitación de la población, y estimulando un salto cualitativo en las condiciones generales de vida en todo el departamento... No existe una "población objetivo" directamente afectada, por lo que, la población objeto del plan, la constituye la totalidad de la población del departamento. Con este plan, se propone retener la población del departamento, especialmente la joven, con la implantación de emprendimientos de alta inversión en el sector y una ocupación sostenida de mano de obra local. Sumado a las condiciones excelentes para el desarrollo de la actividad turística, establece como el uso, el turístico residencial" (IDR, 2010:5-6). Determina la zonificación estratégica distinguiendo siete sectores donde la ocupación se define por diferentes modalidades, densidades y normativas reglamentarias (gráfico 5), que a modo de ejemplo se incorpora los lineamientos para la zona D.
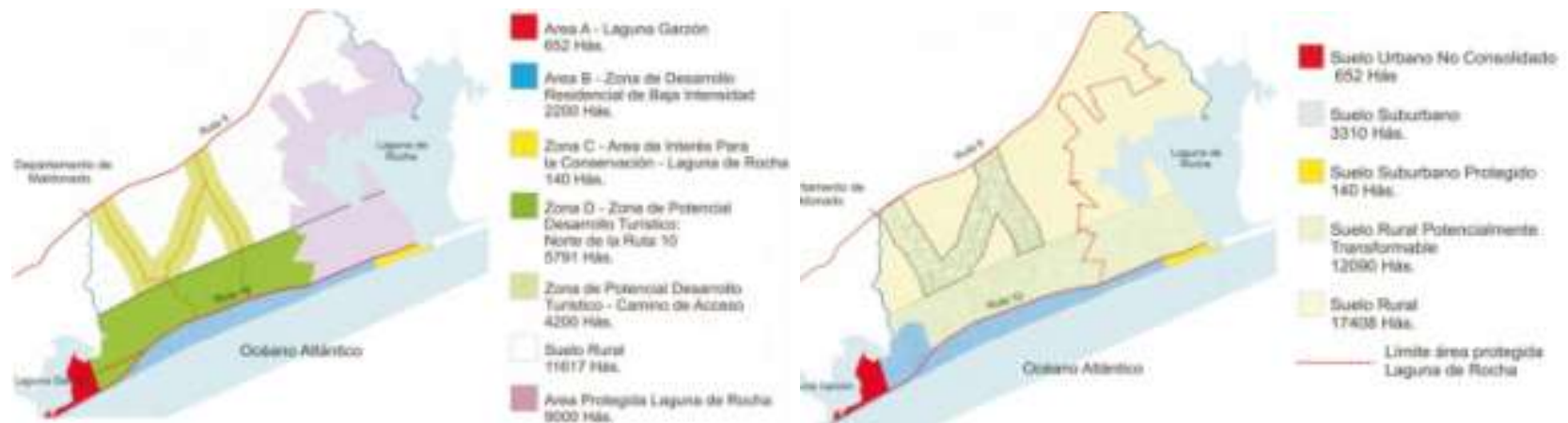

La (Zona D) Zona de Potencial desarrollo turistico:

Área Norte de Ruta 10 - Suelo Rural Potencialmente Transformable. (5.791 hás estimándose una población máxima de 11.000 hab)

Se admitiràn divisiones de suelo que no creen predios independientes inferiores a 5 hás, debiendo tener frente a camino público

Hasta el $20 \%$ del área total del poligono podrán realizarse proyectos de desarrollo turístico residencial con divisiones de suelo en predios menores de 5 hás, incluyendo los del regimen de Propiedad Horizontal, mediante Programas de Actuación Integrada (PAI).

\begin{tabular}{|c|c|c|c|c|}
\hline Ut / hos. & $\begin{array}{c}\text { Naveo } \\
\text { propiedod } \\
\text { comin }\end{array}$ & $\begin{array}{l}\text { S Aked } \\
\text { propiedod } \\
\text { psivado }\end{array}$ & $\mathrm{FOS}=\mathrm{FOO}$ & Allura máx \\
\hline 1 & 505 & $50 \pi$ & $10 \pi$ & $\begin{array}{c}7.5 m \\
2 \text { piantes }\end{array}$ \\
\hline 1.5 & 405 & 405 & $10 \pi$ & $\begin{array}{c}10 \mathrm{~m} \\
3 \text { pianies }\end{array}$ \\
\hline 2 & 705 & $30 \pi$ & $10 \pi$ & $\begin{array}{c}12 \mathrm{~m} \\
4 \text { pianios }\end{array}$ \\
\hline 2.5 & 605 & $20 \%$ & 105 & $\begin{array}{c}12 \mathrm{~m} \\
4 \text { plantos }\end{array}$ \\
\hline 3 & 905 & 105 & $10 \pi$ & $12 \mathrm{c}$ \\
\hline
\end{tabular}

La formulación de los PAI. permitirá transtormar su categoria de suelo rural a suburbano. "El promotor del Programa de Actuación Integrada debera realizar a su costo los estudios que refieran a los siguientes aspectos en referencia al perimetro de actuación y su entorno inmediato: Los impactos previstos en: el medio fisico natural, el medio ambiente, el patrimonio: cultural, histórico, arqueológico, incluyendo el paisaje; los recursos naturales agua, suelo, aire, flora y fauna: La posible afectación de la propuesta en la población, la situación socioeconomica de ésta: las actividades economicas y productivas del area en general. El impacto de la propuesta en el sistema de las infraestructuras, otras dotaciones

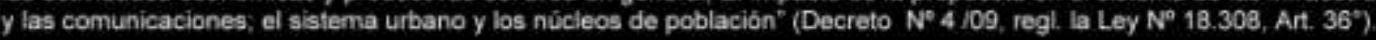

Gráfico 5: Arriba, Zonificación estratégica y categorización de suelos del PLOTLC (IDR, 2010: anexo). Abajo, Síntesis de modalidad de uso del suelo para la zona D del PLOTLC (elaboración propia a partir de IDR, 2010). 


\section{2: EL PAISAJE PROTEGIDO LAGUNA DE ROCHA (MVOTMA / SNAP)}

Según expresan Rodríguez-Gallego et al. (2012a) "La Laguna de Rocha forma parte del sistema de lagunas costeras que se desarrolla en el Este de Uruguay y Sur de Brasil, y se conecta periódicamente con el mar mediante la apertura de un canal en la barra arenosa. El proceso de conexión determina el comportamiento general del sistema. Se trata de un área de destacado valor para la conservación presentando unos 19 ambientes distintos y un total de 109 especies de flora y fauna prioritarias para la conservación. Por otro lado presenta destacados valores culturales, que responden a un proceso histórico de ocupación del territorio desde varios siglos atrás, que hoy se manifiesta en un paisaje marino-costero donde residen dos comunidades de pescadores artesanales que desarrollan sus actividades en la laguna, que a su vez se encuentra rodeada de humedales y campos bajos con ganadería vacuna." (Rodríguez-Gallego et al, 2012a:4). Donde "EI modelo de gestión promocionado actualmente, tiene un eje importante en la promoción de la participación de los diferentes actores cuyos recursos, medios de subsistencia e intereses son afectados. Se atiende a los procesos formales e informales de formación de opinión y negociación entre los actores locales, elaboración de propuestas y toma de decisiones en conjunto con los organismos especializados del Estado. Entre los actores sociales que actúan en la Laguna de Rocha se destacan instituciones del Estado, organizaciones civiles y grupos sociales informales" (Rodríguez-Gallego et al., 2012a:31-32).

El plan de manejo es el instrumento de gestión de más alto nivel para la toma de decisiones y la ejecución de acciones de un área protegida. Es clave para la elaboración de los planes operativos y para el seguimiento y evaluación, definiendo para un horizonte temporal las metas que se pretende alcanzar, con relación a la conservación de la biodiversidad y los aspectos socio-económicos, culturales, e institucionales del área protegida, así como las grandes acciones estratégicas a desarrollar.

En el gráfico 6 se muestra la delimitación terrestre del PPLR con su zona adyacente, así como la visión y objetivos establecidos en el Plan de Manejo.

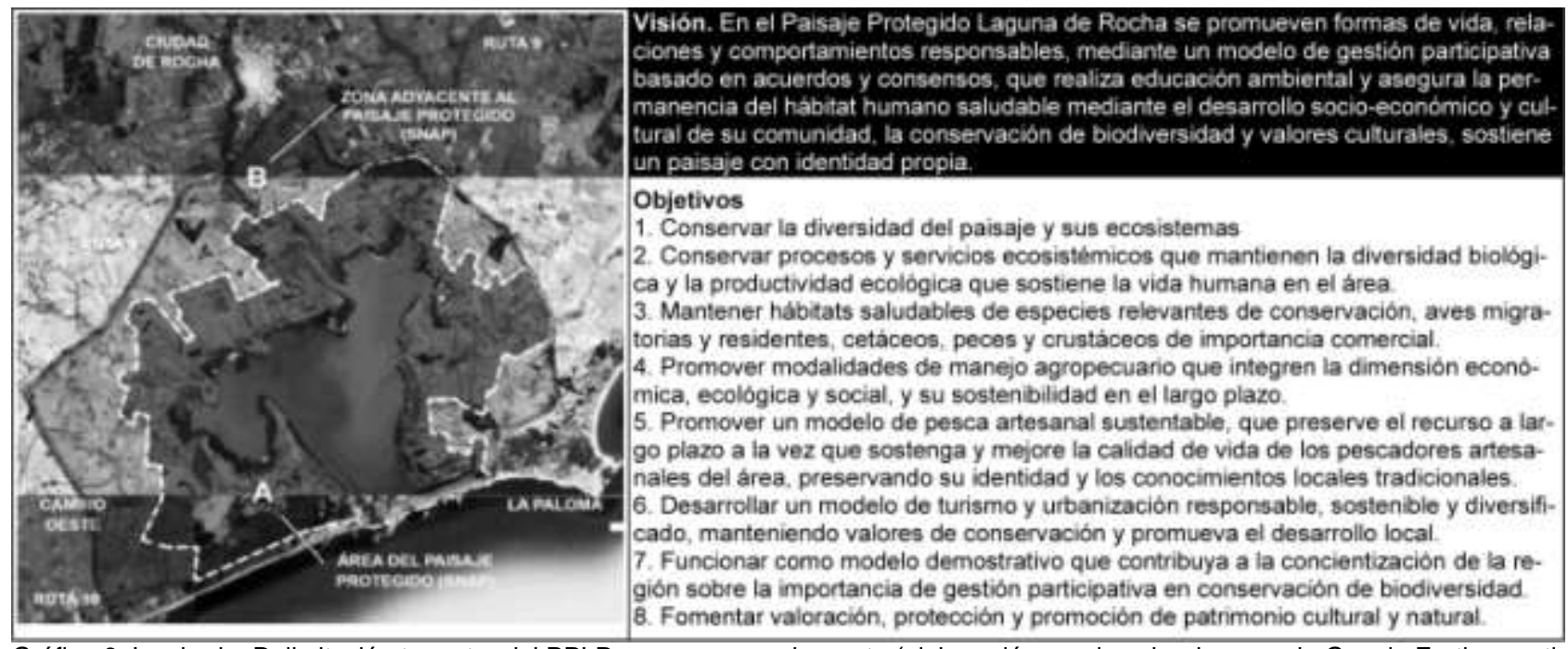

Gráfico 6: Izquierda, Delimitación terrestre del PPLR con su zona adyacente (elaboración propia sobre imagen de Google Earth a partir de Rodríguez-Gallego et al., 2012a). Derecha; Visión y objetivos del Plan de Manejo del PPLR (Rodríguez-Gallego et al., 2012a).

\section{3: JUSTIFICACIÓN}

Del análisis efectuado de los planteos de desarrollo urbano de las intendencias de Maldonado y Rocha (planes locales costeros), confrontados con los lineamientos para la protección y conservación ambiental de las Áreas Protegidas de Laguna Garzón y Laguna de Rocha (SNAP) dependiente del gobierno central (MVOTMA), surgen algunas interrogantes preocupantes incluidas en el gráfico 7.

En primer instancia a escala macroterritorial, según se observa en el gráfico 9, ambos planes (amparados en la LOTDS 18.308), definen grandes sectores del territorio, hasta ahora suelo rural, como potencialmente transformable a suelo de uso suburbano, destinado a emprendimientos turísticos del tipo cerrado. Esta zonificación fue definida sin tener en cuenta las características del ambiente, las actividades productivas existentes, la aptitud del suelo, las preferencias de los usuarios, ni el asentamiento de la población local. Dentro de estas manchas, el lugar y la forma de ocupación que adquieren las UT quedan libradas a la presentación de propuestas por particulares (quienes se encargan de todos los gastos de construcción), siendo la Intendencia la encargada de autorizar su puesta en marcha. En el caso de Maldonado se estableció ocupar hasta el $10 \%$ de la superficie comprendida entre la ruta 10 y la ruta 9 , mientras que en Rocha se estableció 
ocupar hasta el $20 \%$ en la superficie delimitada entre la ruta 10 hasta una línea virtual ubicada a 5 km de la costa hacia el norte.

En segundo lugar, a escala meso dentro del sector Lagunas Costeras de Rocha, en el perímetro delimitado por el APLG (al este), el APLR (al oeste), el arco de playa (al sur) y la línea virtual a $5 \mathrm{~km}$ de la costa (al norte), el PLOTLC introduce urbanizaciones turísticas que ocuparán una superficie aproximada de 8.643 hás, con la incorporación de 28.500 nuevos residentes, sin contar la población local o trabajadora, ni estipular claramente los posibles sitios para su asentamiento.

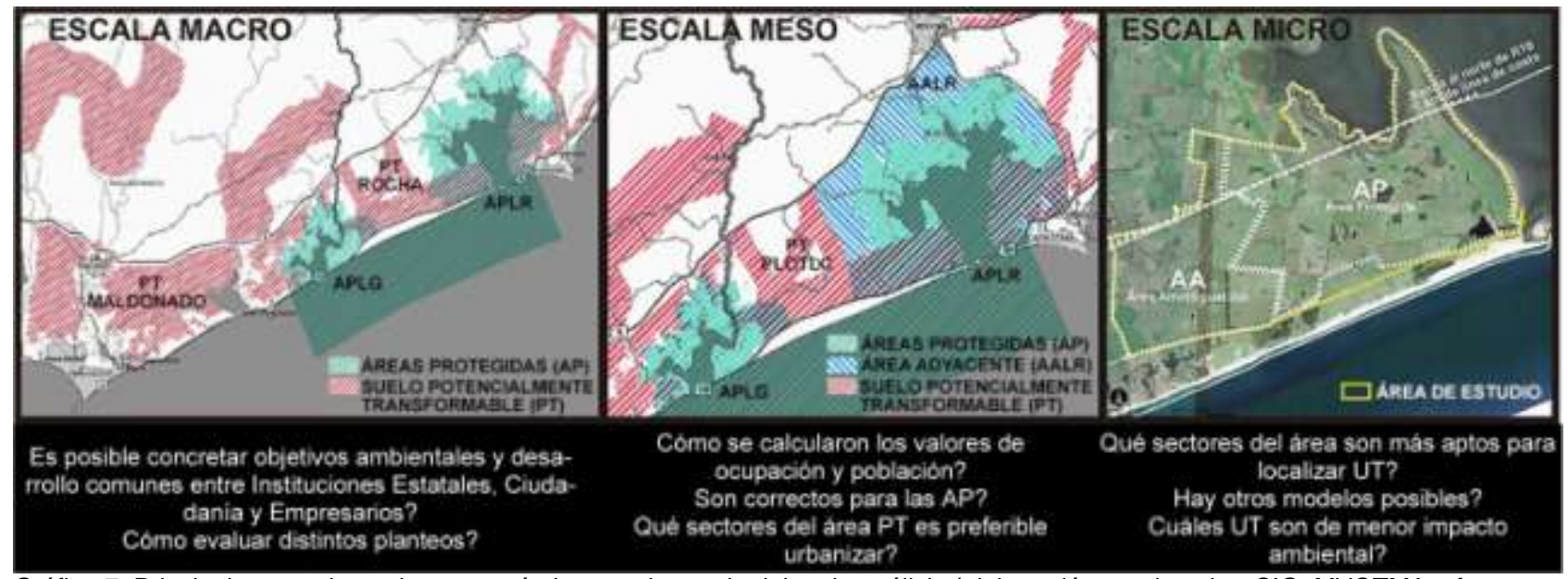

Gráfico 7: Principales cuestionamientos según las escalas territoriales de análisis (elaboración propia sobre SIG, MVOTMA y foto satelital Google Earth).

En tercer lugar a la microescala, dada en la confluencia entre el PPLR (incluyendo su área adyacente), con parte del sector potencialmente transformable a suburbano del PLOTLC, los modelos de UT definidos corresponden exclusivamente a clubes de chacras (con predios privados de 5 hás) y barrios privados (predios privados de $5000 \mathrm{~m}^{2}$ ). Se expresa que se trata de acomodar prudentemente las urbanizaciones y para ello condiciona la implantación mediante un bajo valor de ocupación (20\%) dentro de una gran superficie, apoyado en la creencia de que, como los predios son grandes y baja densidad de población, su impacto será leve. Sin embargo, cuando este fenómeno con capacidad de incidir profundamente en el sistema natural y el paisaje, amenaza con desencadenarse en el territorio contiguo del PPLR, se hace necesario activar otra estrategia para investigar el fenómeno. Para ello es oportuno desarrollar y aplicar metodologías que permitan analizar diferentes dimensiones del problema, evaluar alternativas y seleccionar aquellas con máximos beneficios identificando las desventajas, facilitando la participación de los actores involucrados. El modelo de crecimiento establecido, si bien pareciera ser de bajo impacto sobre el ambiente natural no hay evidencias de ello, dejando sin resolver cuestionamientos relevantes como: Cuáles serían los sitios del sector más aptos para implantar UT? Existen otros modelos capaces de implantarse? Cómo identificar las urbanizaciones más adecuadas, con menor impacto ambiental?

\section{4: OBJETIVOS DEL TRABAJO}

\section{Objetivo general}

Desarrollar y evaluar una metodología capaz de determinar la aptitud de distintas alternativas de urbanizaciones turísticas, en el sector oeste del Paisaje Protegido Laguna de Rocha y en el área adyacente, identificando aquellas que minimicen los impactos sobre el paisaje y el funcionamiento del sistema natural, a la vez que promuevan el desarrollo social y económico de la zona.

\section{Objetivos específicos}

Identificar las zonas preferenciales del sector, para localizar urbanizaciones turísticas, integrando la conservación del sistema natural, aspectos del paisaje visual, la factibilidad de ejecución y la gestión inmobiliaria.

Identificar y seleccionar posibles modelos de urbanizaciones turísticas, aterrizados en propuestas concretas en el área de estudio, con la información requerida para su evaluación.

Evaluar las propuestas de urbanizaciones turísticas para el sector, identificando aquellas que minimicen los impactos negativos sobre el paisaje y el sistema natural, a la vez que, promuevan el desarrollo social y económico de la comunidad local. 


\section{5: METODOLOGÍA}

La estrategia busca articular potencial local con oportunidades emergentes globales, pretende coordinar en objetivos comunes distintas instituciones estatales, ong's y propietarios, fortaleciendo la gobernabilidad y participación ciudadana. Para ello, mediante un trabajo de gabinete y salidas de campo, analizando el marco normativo y antecedentes regionales, apoyado en consideraciones teóricas, trabajos técnicos y experiencias regionales, se diseña una herramienta capaz de integrar distintos especialistas, combinar información (cuantitativa y cualitativa) e incorporar percepciones y opiniones. Se desarrolló adaptando y combinando herramientas existentes en planificación y diseño urbano, evaluación ambiental y teoría de la decisión, mediante procedimientos encadenados: 1) Identificación de las zonas más aptas para localizar UT, 2) Identificación e implantación de las propuestas de UT, y 3) Evaluación ambiental de las alternativas de UT Debido a que el objetivo principal del trabajo refiere a la construcción de la metodología y no a su implementación real, ésta se definió factible de ser modificada y perfeccionada, con la necesaria incorporación de todos los actores que la problemática ambiental requiere. El procedimiento se puso a prueba en el sector costero al Oeste de la Laguna de Rocha, tomando para el estudio dos zonas, una dentro del área del Paisaje Protegido y otra en el área adyacente. El trabajo no se propone realmente urbanizar el sector, sino que se utiliza como soporte para ensayar la metodología y observar "que pasaría si..." se urbanizara el sector.

\section{1: IDENTIFICACIÓN DE ZONAS MÁS APTAS PARA LOCALIZAR URBANIZACIONES TURÍSTICAS}

Para identificar las zonas, se adaptaron y combinaron tres procedimientos metodológicos. El primero, basado en el concepto de aptitud territorial (Fernández, 2000), refiere a identificar en un SIG los sectores del territorio con mejores condiciones para implantar posibles UT considerando posibles impactos, preferencias paisajísticas, así como factibilidad de ejecución y gestión inmobiliaria. El segundo procedimiento se utilizó para combinar y valorar la información que representa esta aptitud, adaptando la metodología de BojórquezTapia et al. (2001), Rodríguez-Gallego et al. (2012b), Rodríguez-Gallego (2004), Estévez (2012) y Nin (2013) confeccionando un modelo multi-atributo con aplicación espacial en un SIG, utilizando información compilada y desarrollada en el Plan de Manejo del PPLR, en las cuatro etapas descriptas en el gráfico 8.

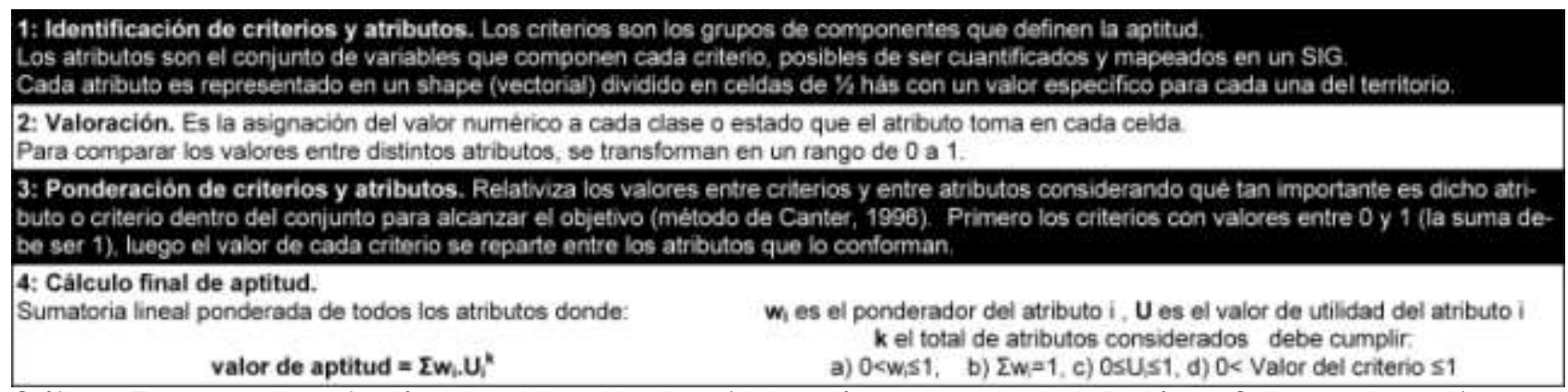

Gráfico 8: Etapas para la confección del modelo multi-atributo (elaboración propia partiendo de Rodríguez-Gallego et al. 2012b)

Finalmente, para obtener una zonificación operativa de la multiplicidad de valores y celdas obtenidas, se realizó el análisis cluster de los valores de resultantes con el método ward o varianza mínima (TransCAD 4.5), obteniendo grupos homogéneos y posibilitando identificar los padrones de mayor aptitud.

\section{2: IDENTIFICACIÓN E IMPLANTACIÓN DE PROPUESTAS URBANO TURÍSTICAS}

La identificación de posibles propuestas surgió del análisis bibliográfico y relevamiento de casos regionales, pautado por las siguientes condicionantes: que respondan a distintas visiones paradigmáticas; que sean posibles de desarrollarse en el sector; que incluya las propuestas del PLOTLC; que sea posible extraer y utilizar la información, para ello se clasifican cualitativamente en sus componentes estructurantes (gráfico 9).

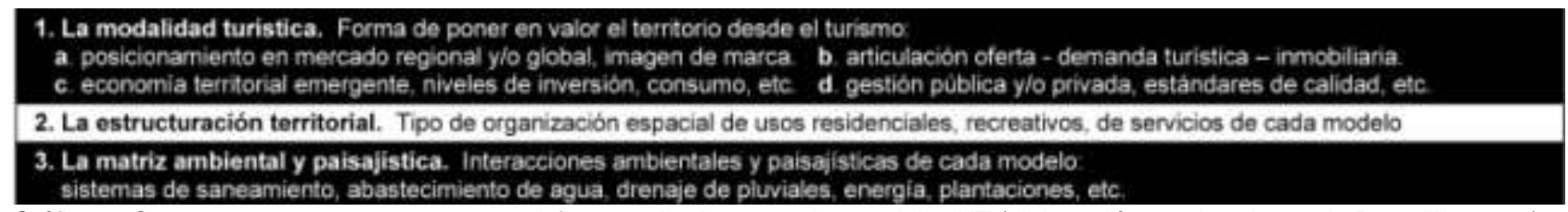

Gráfico 9: Componentes estructurantes, que definen cualitativamente los modelos UT (elaboración propia adaptando Bervejillo, 2010). 
En segunda instancia se realizó la confección, diseño e implantación de las UT en el sector específico de estudio, con la información que las caracteriza para identificar y cuantificar comparativamente sus potenciales impactos ambientales. Teniendo en cuenta algunos supuestos y restricciones (especialmente que cada urbanización debía albergar 1.500 residentes), se identificaron y cuantificaron los componentes principales de cada UT, mediante estimaciones devenidas de la experiencia personal, cruzando distintas fuentes (gráfico 10). Finalmente se representan e implantan gráficamente en las áreas identificadas mediante programas cad, para chequear su correcta funcionalidad.

\footnotetext{
1: Estimación total de población residente y trabajadora de cada UT. (promedio por vivienda, adicionando trabajadores del conjunto)

2: Estimación de cantidad de unidades habitacionales (UH) necesarias para albergar 1.500 residentes.

3: Identificación y cuantificación de componentes arquitectónicos de cada UH (vivienda, parriliero, jardineria, camineria, cocheras,

etc.) y de la infraestructura general del conjunto (infraestructura vial, paisajistica, de saneamiento, energia, seguridad, etc)

4: Superficie total de $\mathrm{d}$ UT, según cantidad de población, cantidad de UH, tamaño de predios privados e infraestructura del conjunto

5: Valor total de inversión de las UT, sumando componentes arquitectónicos e infraestructurales (según precios estándar del mercado) Gráfico 10: Procedimiento realizado para obtener la información cuantitativa de las UT (elaboración propia).
}

\section{3: EVALUACIÓN DE LAS ALTERNATIVAS DE URBANIZACIONES TURÍSTICAS}

Para obtener la evaluación de las UT, se construyó un nuevo modelo muti-atributo (en punto 5.2) basado en el concepto de aptitud, en este caso busca establecer la mejor relación entre ambiente y cada UT o cuál UT cumple mejor con el desarrollo sustentable. En concordancia con la visión del plan de manejo del PPLR, se define como "...La permanencia de un hábitat humano saludable mediante el desarrollo socio-económico y cultural de su comunidad, la conservación de la biodiversidad y de los valores culturales, que sostienen un paisaje con identidad propia" (Rodríguez-Gallego, 2012a:27).

La aptitud es representada por una batería de indicadores (criterios y atributos). Los criterios que componen el DS o la sustentabilidad, se establecieron de acuerdo a la definición planteada, en consonancia con la bibliografía analizada en la dimensión natural, la dimensión social, la dimensión económica, incluyendo la dimensión del paisaje (basado en la consideración que se trata de un paisaje protegido) y para ellos los supuestos utilizados fueron:

En la dimensión natural: el mantenimiento de la diversidad de ambientes y ecosistemas característicos del sector permite conservar los procesos y servicios ecosistémicos que mantienen la diversidad biológica y la productividad ecológica que además sostienen las actividades turísticas y agropecuarias en el área. Así mismo, manteniendo hábitats saludables se conservan las especies relevantes para el área protegida (Rodríguez-Gallego, 2012a, Benseny 2006).

En la dimensión social: el poblamiento y la permanencia de la población de este sector rural en un hábitat humano saludable y bajo modelos inclusivos de todos los sectores sociales evitando la segregación socioespacial, generando empleos genuinos para la población local y minimizando la zafralidad estacional. (ERC 2012, Acuña et al. 2011, Benseny 2006, Fernández 2000).

En la dimensión económica: la distribución equitativa de costos y beneficios de las inversiones inmobiliarias y la dinamización del mercado local. Que implique a nivel departamental, el incremento de los ingresos por las tasas de ocupación territorial, minimizando los egresos por servicios públicos y control ambiental (ERC 2012, Acuña et al. 2011, Benseny 2006, Fernández 2000, Arocena 1997).

En la dimensión del paisaje: la conservación del paisaje mediante la distribución y localización equilibrada de actividades y asentamientos humanos en armonía con el territorio. A partir de mantener sus valores, la diversidad de configuraciones de ecosistemas y ocupaciones humanas y minimizando el impacto visual de las urbanizaciones e infraestructuras (Rodríguez-Gallego, 2012a, Benseny 2006).

Los atributos que componen cada criterio o dimensión, se corresponden con los posibles impactos de las UT sobre el ambiente (capaces de ser mensurados) y surgieron de bibliografía especializada de la región (Nin 2013, Rodríguez-Gallego 2012a, Bervejillo 2010 y de Álava 2007).

Para hacer comparables los valores de los distintos atributos se construyeron curvas de utilidad transformando todos los valores reales al rango 0 (menos apto) - 1 (más apto).

El peso relativo entre criterios es equivalente $(0.25)$ interpretando que para la definición de DS establecida, el desempeño de todas las dimensiones es igual de importante. Las ponderaciones de los atributos de cada dimensión, surgieron del procedimiento de comparación de a pares jerarquizados, de acuerdo a la contribución del DS esperado, donde la suma de éstos debe igualar el valor del ponderador asignado al criterio que los aglutina. Por otro lado, se entiende que los dos sectores analizados (AP y AA) no pueden evaluarse de igual forma y deben evidenciar distinta sensibilidad a los impactos, introduciendo otro ponderador que afecta 
el valor de cada atributo relativizando los impactos (gráfico 11).
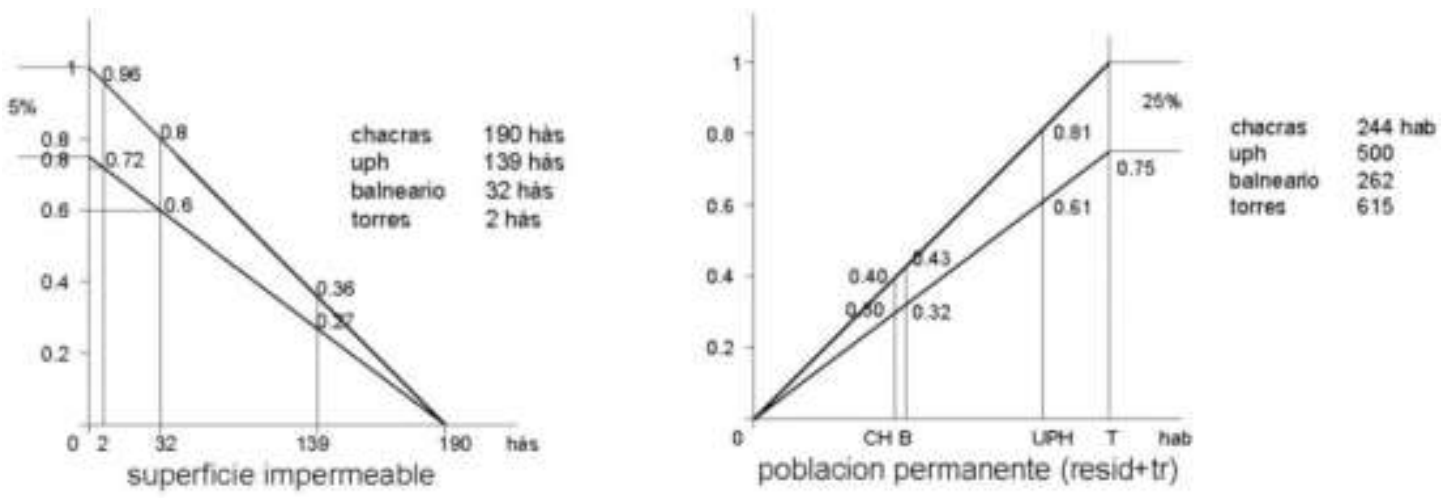

Gráfico 11: Ejemplos de curvas de utilidad. Expresan la magnitud y sentido del impacto de los atributos y su transformación a valores entre 0 y 1 . Contiene los valores del ponderador que relativiza impactos en el AP o en el AA (elaboración propia).

Finalmente, se construyó una matriz en una planilla de cálculo, con los valores de todos los atributos y ponderaciones obteniendo a través de la suma lineal ponderada la aptitud total y la de cada dimensión,

Para apoyar los resultados obtenidos a modo de exploración y análisis se modifican los valores que ponderan los criterios, favoreciéndolos con mayor peso uno a uno.

\section{6: RESULTADOS \\ 6.1: IDENTIFICACIÓN DE ZONAS MÁS APTAS PARA LOCALIZAR URBANIZACIONES TURÍSTICAS}

Los atributos seleccionados para el criterio Capacidad del territorio para albergar urbanizaciones, refieren a la conservación de biodiversidad, siendo: zonificación de usos del PPLR (del Plan de Manejo), probables sitios arqueológicos, erodabilidad de suelos, pérdida de productividad agrícola (Suelos CONEAT, se evita ocupar suelos más productivos), coberturas del suelo (por conservación y compatibilidad con uso de residencia) y ubicación altimétrica (evita zonas inundables, distanciándose de las lagunas). El criterio Preferencias de Paisaje, contiene atributos referidos a posibles preferencias de usuarios para elegir sitio de residencia, siendo: zonas desde donde es posible observar algún sector del Océano Atlántico, Laguna de Rocha y Laguna de las Nutrias), otros tres por la cercanía a estos mismos sitios y proximidad a cursos de agua y lagunas, por su valor paisajístico. El criterio Accesibilidad al sitio, contiene atributos de factibilidad económica y construcción, siendo: accesibilidad a rutas y proximidad a caminos internos existentes.

En el gráfico 12 se presentan tres atributos como ejemplo del mapeo según la valoración de preferencias.

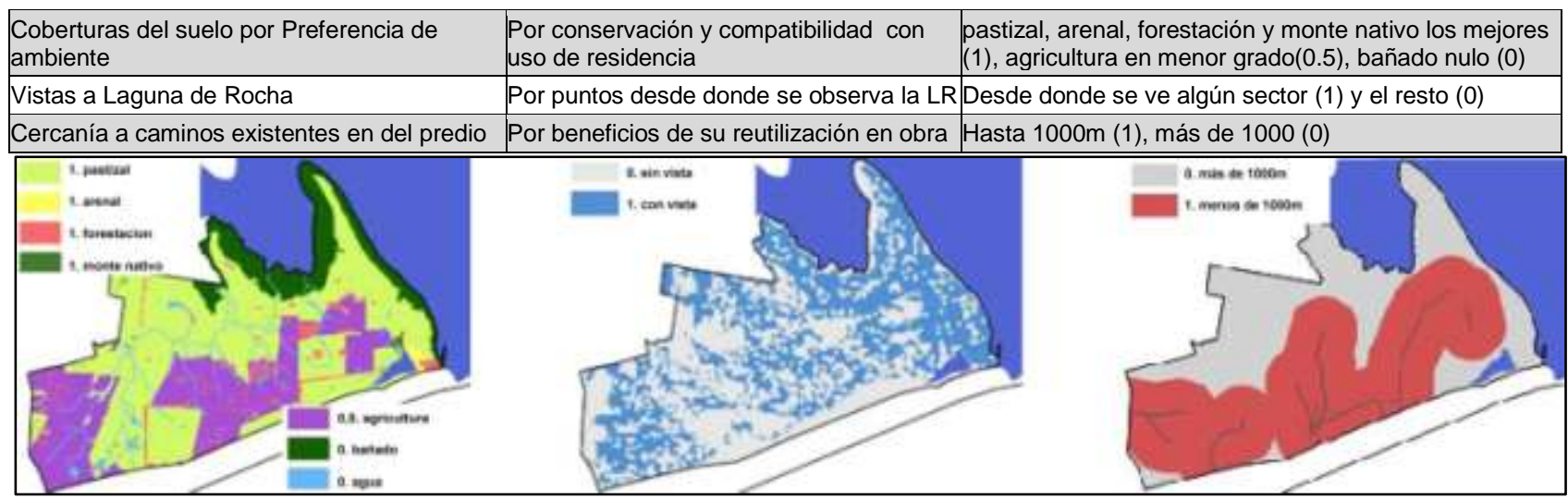

Gráfico 12: Ejemplo del mapeo según la valoración de preferencias para los atributos Coberturas del suelo por Preferencia de Ambiente, Vistas a Laguna de Rocha y Cercanía a caminos existentes en del predio (elaboración propia).

Los criterios y atributos se ponderaron empleando el procedimiento de comparación de a pares jerarquizados. Teniendo en cuenta que el objetivo es conservar la biodiversidad y el paisaje, se entendió necesario establecer pesos relativos a los criterios, donde la capacidad del territorio para albergar urbanizaciones debía ser el más valorado, seguido por preferencias paisajísticas y accesibilidad al sitio. La modelación multicriterio a través de la sumatoria lineal ponderada dentro del SIG permitió obtener la aptitud del territorio analizado para las UT, obteniéndose un nuevo mapa con valores que van entre 0.2359 a 
0.8440 para cada una de las 60.680 celdas que lo componen. El análisis cluster en 5 clases permitió obtener el mapeo final acorde a la escala de la división catastral (gráfico 13).

\begin{tabular}{|c|c|c|c|c|}
\hline Criterios & $\begin{array}{c}\text { Ponderación } \\
\text { criterios }\end{array}$ & Atributos & $\begin{array}{l}\text { Ponderación } \\
\text { Atributos }\end{array}$ & \\
\hline \multirow{6}{*}{$\begin{array}{l}\text { Capacidad del } \\
\text { territorio para } \\
\text { albergar UT }\end{array}$} & \multirow{6}{*}{0.5} & Zonificación de usos del PPLR & 0.107 & \\
\hline & & Probables sitios arqueológicos & 0.143 & \\
\hline & & Erodabilidad de suelos & 0.071 & \\
\hline & & Pérdida de productividad agricola & 0.095 & \\
\hline & & Coberturas del suelo & 0.048 & \\
\hline & & Ubicación altimetrica & 0.036 & \\
\hline \multirow{7}{*}{$\begin{array}{l}\text { Preferencias } \\
\text { paisajisticas }\end{array}$} & \multirow{7}{*}{0.33} & Proximidad a la costa atlántica & 0.040 & \\
\hline & & Proximidad a la Laguna de Rocha & 0.040 & \\
\hline & & Proximidad a Laguna de las Nutrias & 0.040 & \\
\hline & & Prox a cursos y lagunas internas & 0.013 & \\
\hline & & Cuenca visual Oceano Atiántico & 0.067 & \\
\hline & & Cuenca visual Laguna de Rocha & 0.067 & \\
\hline & & Cuenca visual $L$ de las Nutrias & 0.067 & \\
\hline \multirow{2}{*}{$\begin{array}{l}\begin{array}{l}\text { Accesibilidad al } \\
\text { sitio }\end{array} \\
\end{array}$} & \multirow{2}{*}{0.17} & Proximidad desde rutas principales & 0.083 & \\
\hline & & Proximidad a camineria interna & 0.083 & La \\
\hline
\end{tabular}

Gráfico 13: Izquierda, resumen de criterios, atributos y valores de los ponderadores utilizados en el modelo. Derecha, mapeo de resultante para la identificación de las zonas más aptas para localizar UT surgidas del SIG (elaboración propia).

\section{2: IDENTIFICACIÓN E IMPLANTACIÓN DE PROPUESTAS URBANO TURÍSTICAS}

Se obtuvieron cuatro modelos: Chacras agroturísticas, Barrios cerrados (UPH), Balnearios abiertos y Torres en altura. Posteriormente se identificaron y cuantificaron los componentes principales de cada UT para 1500 residentes, vinculando residentes por vivienda, cantidad de trabajadores, cantidad de viviendas, superficie de predios, infraestructura general, conjunto, construcciones y valores de inversión. Las estimaciones realizadas se digitalizaron y manipularon a través de programa de diseño (cad) y se insertaron en los sitios seleccionados según las superficies obtenidas de cada tipo de urbanización. Todos los resultados obtenidos del proceso se presentan en figura 14.

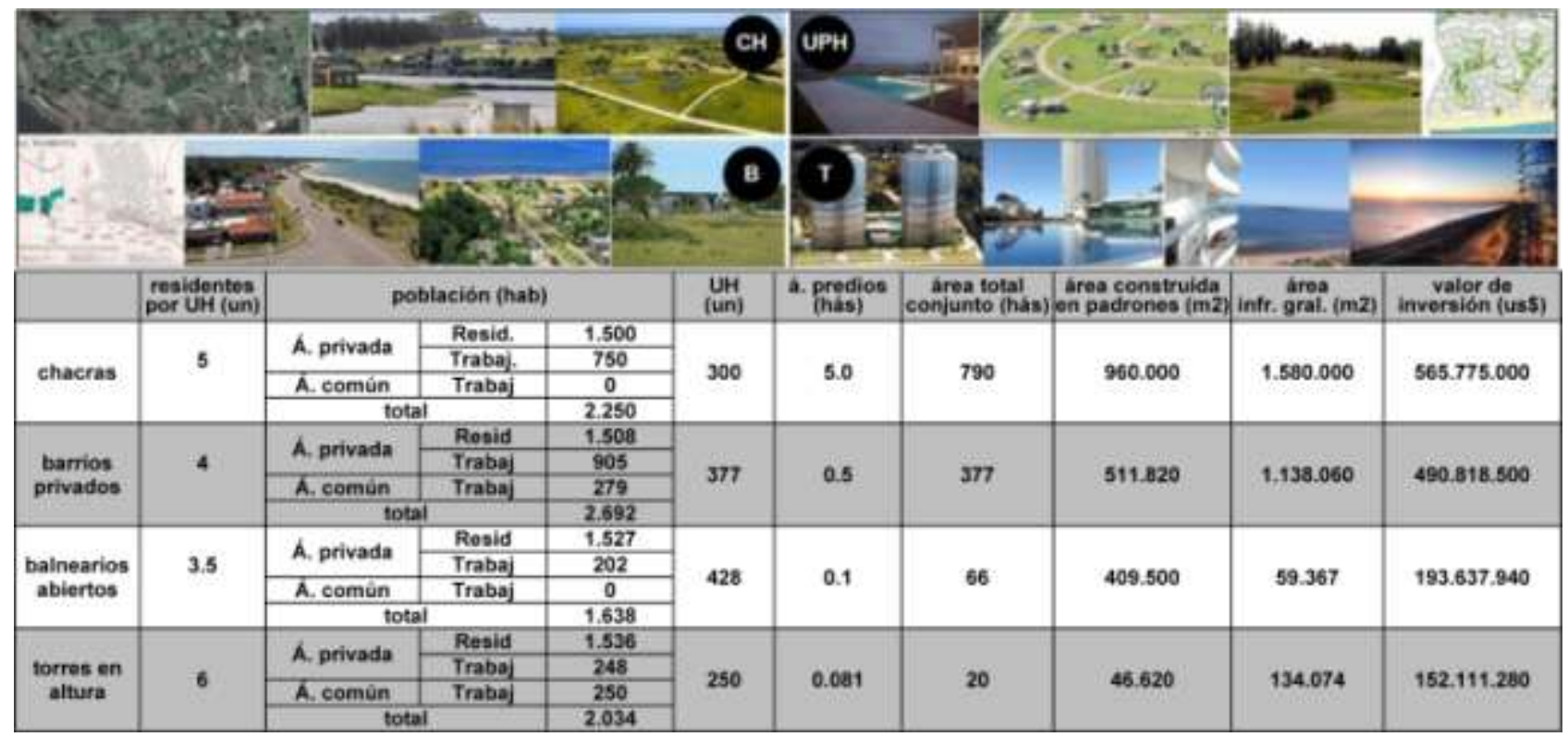




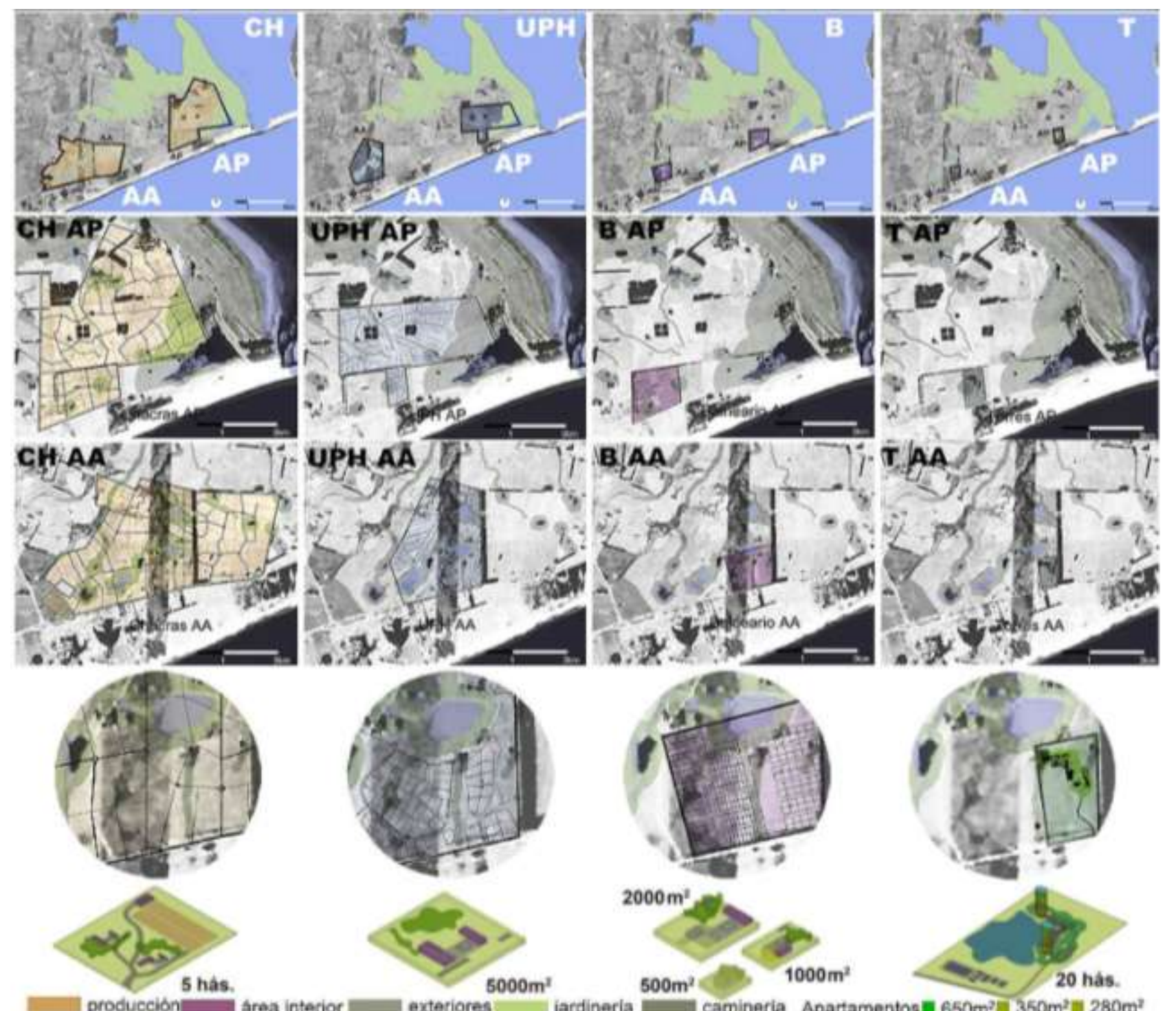

Gráfico 14: De arriba hacia abajo, 1) imágenes de modelos resultantes, Chacras agroturísticas (CH), Barrios cerrados (UPH), Balnearios abiertos (B) y Torres en altura (T) (elaboración propia con imágenes promocionales de emprendimientos). 2) Resumen de valores resultantes de todas las magnitudes involucradas para cada tipo de UT. 3) Graficación a distintas escalas de la ocupación territorial de cada UT en los padrones seleccionados del AP y AA (elaboración propia sobre foto de Google Earth).

\section{3: EVALUACIÓN DE LAS ALTERNATIVAS DE URBANIZACIONES TURÍSTICAS}

El análisis multi-atributo permitió evaluar para cada modelo de urbanización turístico en las dos zonas estudiadas cuán sustentables son, en base a una batería de atributos que describen la dimensión ambiental, social, económica y paisajística. Se identificaron 29 impactos posibles de las UT (positivos o negativos) que se sintetizaron en 22 indicadores o atributos. Siete para la dimensión natural, cuatro para el paisaje, cinco para lo social y seis para lo económico.

En primer instancia se asignaron los ponderadores de los pesos relativos entre criterios y posteriormente atributos. En este trabajo se consideró que la sustentabilidad está definida por el mismo peso relativo entre las cuatro dimensiones ambientales. El valor que asume el ponderador de cada atributo que constituye cada criterio se realizó por el procedimiento de comparación de a pares, teniendo en cuenta que el valor de la suma de los ponderadores de cada atributo para un criterio, debe ser igual al valor del ponderador asignado al criterio en el paso anterior, en este caso 0.25 .

Para el criterio Dimensión natural, se consideraron como más relevantes, el denominado superficie de ocupación de la UT / superficie del AA o AP (que corresponde al porcentaje de ocupación del suelo), superficie de jardinería exótica y densidad de población, debido a que aglutinan varios impactos relevantes. Le siguen superficie impermeable que refiere al proceso erosivo y cantidad de autos debido a los daños sobre la fauna y otras molestias. Finalmente, se ubicó largo de la red de saneamiento como indicador de posible contaminación, superficie de ventanas por vivienda / superficie total ocupada de la UT (o densidad de efecto reflejo) 
relacionado a los accidentes de aves.

Para el criterio dimensión Paisajística, se consideró de más importancia el impacto visual de las UT desde el entorno representado por el atributo superficie de cuenca visual / superficie de cada sitio (AP o AA) con, seguido por barrera visual que fue estimado como la superficie de la UT / superficie de cada sitio (AP o AA), cambio del imaginario colectivo y densidad de focos de iluminación que fue estimado como el número de viviendas / hás de superficie UT).

Para el criterio Dimensión social, se consideraron como más relevantes población permanente de trabajadores y propietarios y el impacto de la segregación o mezcla social estimado como la superficie de espacio público de la UT / superficie total de la UT, les sigue Población trabajadora total por la importancia del poblamiento del área rural con la generación de empleos. Finalmente, población trabajadora permanente / población trabajadora estacional o empleos zafrales, junto a cantidad de autos por día por las molestias por congestión y ruido en alta temporada.

Para el criterio Dimensión económica, se consideraron de mayor importancia tres atributos en conjunto, ingresos municipales, concerniente al beneficio del gobierno departamental, gasto promedio de la población permanente, por la distribución de éste ingreso hacia la población local y costo según la dificultad de control ambiental, seguido por egreso municipal por infraestructura y valor total de inversión de UT. En el gráfico 15 se presentan los resultados obtenidos para las ponderaciones de criterios y atributos.

A partir de los cálculos numéricos, gráficos y otras estimaciones realizados se valoraron y transformaron los atributos para cada tipo de urbanización. La valoración se asignó de acuerdo a la contribución al concepto de DS en las cuatro dimensiones descritas en la metodología, la estimación de los valores relativos entre un mismo atributo para el Área Protegida (AP) o el Área de Amortiguación (AA) se asignó según el análisis e interpretación del Plan de Manejo, especialmente de las condicionantes planteadas en la zonificación para la gestión de usos.

Resulto que considerando el mismo peso de todos los criterios, en el AP los modelos más aptos a implantar serían Balnearios o Torres, descartando Barrios privados y Chacras, mientras que en el AA serían Balnearios, Torres o Barrios privados, descartando las Chacras (gráfico 15). Se puede decir que para minimizar impactos negativos en la dimensión Natural se debería optar por las Torres (para AA y AP), mientras que en la dimensión Paisaje deberían ser Balnearios (para AA y AP). Así mismo, para maximizar beneficios económicos se debería optar por Barrios privados o Torres (para AA y AP), mientras que en lo Social deberían ser Balnearios o Torres (para AA y AP) incluyendo las Chacras en el AA.

Los resultados obtenidos con otros valores entre criterios se observan en el gráfico 15 y refieren a considerar: 1) se agrupan lo natural con paisaje, de forma que sean la tercera parte, 2) se prioriza conservación natural y paisaje, 3) se prioriza lo social y 4) se prioriza lo económico. 


\begin{tabular}{|c|c|c|c|c|c|c|c|c|c|c|c|c|c|c|c|c|}
\hline \multicolumn{3}{|c|}{ CRITERIOS } & \multicolumn{2}{|c|}{$\begin{array}{l}\text { PONDERACION } \\
\text { CRITERIOS }\end{array}$} & \multicolumn{7}{|c|}{ ATRUBUTOS } & \multicolumn{2}{|c|}{$\begin{array}{l}\text { PONDERACION } \\
\text { ATRIBUTOS }\end{array}$} & \multicolumn{3}{|c|}{$\begin{array}{l}\text { PONDERADOR POR } \\
\text { UBICACION (AA O AP) }\end{array}$} \\
\hline \multirow{7}{*}{\multicolumn{3}{|c|}{ Dimensión natural }} & \multirow{7}{*}{\multicolumn{2}{|c|}{0.25}} & \multicolumn{7}{|c|}{ Superficie de ocupación de la UT / Superficie del AA o AP } & \multicolumn{2}{|c|}{0.058} & \multicolumn{3}{|c|}{ disminuye ai $5 \%$ de AP } \\
\hline & & & & & \multicolumn{7}{|c|}{ Superficie impermeable } & \multicolumn{2}{|c|}{0.038} & \multicolumn{3}{|c|}{ diaminuye al $75 \%$ de AP } \\
\hline & & & & & \multicolumn{7}{|c|}{ Superficie de jardineria exótica } & \multicolumn{2}{|c|}{0,048} & \multicolumn{3}{|c|}{ disminuye al $25 \%$ de Al } \\
\hline & & & & & \multicolumn{7}{|c|}{ Largo de la red de saneamiento } & \multicolumn{2}{|c|}{0,014} & \multicolumn{3}{|c|}{ disminuye al $50 \%$ de Af } \\
\hline & & & & & \multicolumn{7}{|c|}{ Superficie de ventanas por vivienda / superficie total ocupada de UT } & \multicolumn{2}{|c|}{0,014} & \multicolumn{3}{|c|}{ disminuye al $50 \%$ de AF } \\
\hline & & & & & \multicolumn{7}{|c|}{ Cantidad de población / Superficie del AA o AP } & \multicolumn{2}{|c|}{0.048} & \multicolumn{3}{|c|}{ disminuye al $25 \%$ de Af } \\
\hline & & & & & \multicolumn{7}{|c|}{ Cantidad de autos } & & 029 & dismint & aye at 25 & * de AP \\
\hline & & & & & Superficie d & cuenc: & visual de & cada U & superfic & de cad & sitio & & 100 & disminu & yye al 50 & $\$ 6$ de AP \\
\hline Dimensión & fel paisa & & 0.25 . & & Superficie o & la UTI & superficie & de cad & tio (AP & AA) & & & 075 & disminc & sye al 25 & $\%$ de AP \\
\hline Dimension & del paisa & & 0.20 & & Cambio de & magina & io colectis & & & & & & 025 & desmins & $y=$ at 25 & 16 de AP \\
\hline & & & & & Numero de & ivienda & I superf & ie de U & & & & & 050 & disminu & ye al 50 & $\%$ de AP \\
\hline & & & & & Población p & manen & te (trabaj. & dores $y$ & opietarí & & & & 070 & disminu & sye al 75 & $\%$ de $A A$ \\
\hline & & & & & Poblacion t & bajado & a total (pe & manen & + zalrale & & & & 055 & & igual & \\
\hline Dimensión & ocial & & 0.25 & & Población t & abajado & a perman & ente / $P$ & trabaja & lora esta & cionat & & 031 & & igual & \\
\hline & & & & & Superficie d & espaci & público & de la UT & superfici & total de & a UT & & .063 & & igual & \\
\hline & & & & & Cantidad do & autos p & or dia (res & identes & rabajad: & (os) & & & 031 & ditamins & yye al 25 & \% de AP \\
\hline & & & & & Costo total & e invers & ón de ut & & & & & & 025 & & igual & \\
\hline & & & & & Gasto prom & dia de : & oblación & permane & & & & & 058 & & igual & \\
\hline Dimensión & conómi & & 0.25 & & Ingresos m & nicipale: & & & & & & & 058 & desmins & ye at 75 & $\%$ de AP \\
\hline & & & & & Egreso mur & ipal po & infraestr & jectura & & & & & 050 & & igual & \\
\hline & & & & & Costo segu & la difica & tad de cc & ntrol an & antal & & & & 058 & dismine & sye al 50 & $\%$ de AP \\
\hline & & & & & & & & & & DNo & $95 \times$ PS & JEOPI & 1050 & 331 & 035 & \\
\hline pond. & abonic & nes. & DNONE & $f / \mathrm{Pr}$ & DSUE 0.26 & Dsen & W: DE 0 & & 0.302 & 0.360 & 0.384 & 0.408 & 0.333 & 0.481 & 0.586 & 0.510 \\
\hline & & & AA & & & & $P$ & & & & 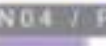 & PSTER & 1. ESO & TII. DE & & \\
\hline & cariat & $m$ & menes & $n=$ & trocust & $m$ & menses & $n=$ & 0.149 & 0.236 & 0.299 & 0.246 & 0.238 & 0.464 & 0.691 & 0.587 \\
\hline senting & 0.004 & 0.026 & 0.062 & 0.065 & 0.015 & 0.076 & 0.170 & 0.220 & & & Q17? & त्वस्I & 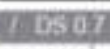 & IIE & & \\
\hline 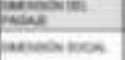 & $\frac{0.037}{0.104}$ & $\frac{0.064}{0.063}$ & $\frac{0.079}{0.104}$ & $\frac{0.011}{0.113}$ & $\frac{0.083}{0.084}$ & $\begin{array}{l}0.151 \\
0.057\end{array}$ & $\begin{array}{l}0.197 \\
0.107\end{array}$ & $\frac{0.074}{0.106}$ & 0.348 & 0.279 & 0.392 & 0.411 & 0.322 & 0.329 & 0.500 & 0.489 \\
\hline 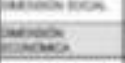 & $\begin{array}{l}0.104 \\
0.104\end{array}$ & $\begin{array}{l}0.063 \\
0.164\end{array}$ & $\begin{array}{l}0.104 \\
0.122\end{array}$ & 0.11 & $\frac{0.084}{0.119}$ & 0.193 & 0.152 & 0,185 & & & gXlas & 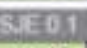 & DSol & II DES & & \\
\hline apritue nua & 0.249 & 0.318 & 0.356 & 0.35 & 0.301 & 0.478 & 0.627 & 0.585 & 0.350 & 0.522 & 0.435 & 0.506 & 0.406 & 0.653 & 0.616 & 0.679 \\
\hline
\end{tabular}

Gráfico 15: Resumen de criterios y atributos con valores y ponderadores utilizados en la evaluación. Abajo, Izquierda, resultados finales de aptitud de las UT (totales y por dimensión) en AP y AA. Derecha, resultados de aptitud modificando la valoración de los criterios.

\section{7: DISCUSIÓN}

El foco principal del trabajo estuvo puesto en desarrollar una metodología capaz de abordar un conflicto ambiental de alta complejidad a través de un caso real referido al desarrollo urbano (Intendencias de Maldonado y Rocha) frente a la protección y conservación ambiental (Áreas Protegidas de Laguna Garzón y Laguna de Rocha del SNAP). El análisis del caso derivo en tres cuestionamientos que guiaron el trabajo: ¿cuáles serían los sitios de este sector más aptos para implantar UT?, ¿existen otros modelos, capaces de implantarse?, ¿cómo identificar las UT más adecuadas y de menor impacto ambiental? Estas se tradujeron en tres objetivos específicos encadenados que fueron concretados, identificando los sectores más aptos para urbanizar, seleccionando posibles modelos de UT, incorporándolos en los sectores identificados, posibilitando la evaluación ambiental y seleccionando las más sustentables.

Puede afirmarse que las UT balnearios y torres son las más aptas en todos los escenarios planteados (AA y AP), exceptuando dos casos. En el de mayor conservación la UT balneario es exclusivamente la de mayor aptitud (en AA y AP), por lo que si se tratara de priorizar la conservación de lo natural y el paisaje sería el balneario la más indicada para implantar, mientras que si se pretende conservar exclusivamente lo natural serían las torres. El otro caso, en el que se prioriza el criterio económico, la UT barrio privado se ubica en la primer posición (en AA y AP), desapareciendo la urbanización en balneario del AA, por lo que lo más adecuado para obtener mayores beneficios económicos sería urbanizar con UT de barrios privados.

Como ya fue puntualizado, la investigación buscó poner a prueba una propuesta metodológica. Por tanto, los resultados obtenidos del presente trabajo deben ser entendidos como una primer aproximación en la aplicación de metodologías multi-atributo para la selección de alternativas urbanísticas. Para una evaluación fehaciente en instancias de toma de decisiones las soluciones a los problemas ambientales de esta naturaleza, deben ser incorporados grupos interdisciplinarios con diversos especialistas, los actores involucrados y análisis teórico-prácticos basados en la realidad que retroalimenten nuevas soluciones. 
Si bien los resultados obtenidos son relevantes, es en este paso metodológico donde se encuentran las mayores dificultades para tomarlos en cuenta, debido a la introducción de posibles errores. La principal dificultad conceptual refiere a que, la evaluación de las propuestas, está directamente relacionada al concepto de "desarrollo sustentable", donde la valoración de sus distintos componentes, para su aplicación en propuestas concretas no es posible realizarla por una sola persona y desde el gabinete. Si bien se propone explícitamente una definición del concepto que se expresa en los valores que asumen las variables, el trabajo apuesta a una definición que surja de la discusión colectiva y consensuada de todos los actores involucrados.

\section{8: CONCLUSIONES}

Se puede concluir que la metodología planteada se destaca por posibilitar sustituir elecciones intuitivas por justificadas ante el difuso concepto de desarrollo ambiental sustentable en general, así como su implicancia dentro de las distintas dimensiones que lo componen en particular. En su utilización se mostró flexible y práctica para seleccionar los sitios a urbanizar, comparar modelos de UT, posibiltando incorporar el concepto de DS mediante los valores que asumen las variables, habilitando comparar y discutir el significado de este concepto para otras posibles visiones. Así mismo, debido a que todas las variables, valores y procesos son explícitos es especialmente favorable para utilizar en procesos participativos ya que los resultados pueden ser revisados y modificados en búsqueda de alcanzar acuerdos y decisiones de consenso.

Se destaca su versatilidad ya que puede ser aplicada con otros objetivos tales como establecer límites de crecimiento, seleccionar alternativas de sitios de implantación, evaluar cambios de manejo de una misma propuesta, explorar variantes de una misma propuesta y crear nuevas. Futuros trabajos podrían incorporar avances tecnológicos de edificios e infraestructura urbana relevantes, el balance de energía, los materiales, los procedimientos constructivos u otros. También es necesario considerar avances del conocimiento para la mejora en herramientas de control y vigilancia ambiental, así como la amplificación de la educación ambiental, que posibilite un cambio cultural en las nuevas generaciones, con ciudadanos más respetuosos y participativos.

A la luz de los resultados obtenidos, opuestos al planteo de la IDR, motivan un análisis profundo e integral del caso posibilitando una mejor coordinación entre las instituciones estatales, fortaleciendo la gobernanza, clarificando el dialogo entre los gobernantes (o sociedad política) y la comunidad (o sociedad civil), mejorando la capacidad de gestión para el área.

\section{9: BIBLIOGRAFÍA}

Acuña C, de Souza L, Gadino I, Leicht E, Musso C, Vainer D y Varela A. 2011. Aglomeración Maldonado Punta del Este - San Carlos. Enfoques y propuestas hacia un Modelo transformador. Instituto de Teoría y Urbanismo. Facultad de Arquitectura, UdelaR. Edit. Mosca. ISBN 978-9974-99-045-6. Montevideo.

Allen A. 1998. Texto de apoyo al curso de Posgrado en Gestión y Planificación Urbana. Módulo 2. Maestría en Ordenamiento Territorial. Facultad de Arquitectura, Universidad de la República. Montevideo.

Améndola G. 2000. La ciudad postmoderna. Celeste Ediciones. ISBN: 84-8211-239-2. Madrid.

Arocena R. 1997. Globalización, integración y desarrollo local apuntes para la elaboración de un marco conceptual. En Madoery O y Vázquez Barquero A (eds.): Rev. Persona y Sociedad, ILADES, Santiago, Chile. Transformaciones globales, Instituciones y Políticas de desarrollo local. Edit. Homo Sapiens, Rosario.

Articardi J. 2014. Urbanización de la Costa de Oro. El fin de una utopía. El País Cultural El País digital, 06 junio 2014. Montevideo. Disponible en:http://www.elpais.com.uy/cultural/utopia-costa-oro-urbanizacion.html

Benseny G. 2006. El espacio turístico litoral. Aportes y Transferencias. Vol. 10, ㄲo 2:102-122. Universidad Nacional de Mar del Plata. Disponible en:http://rdalyc.uaemex.mx/src/inicio/ArtPdfRed.jsp?iCve=27610208

Bervejillo F. 1996. Territorios en la globalización. Cambio global y estrategias de desarrollo territorial. Inst. Latinoamericano yCaribe Planif. Económica y Social. Doc.96/34. Serie Ensayos. Disponible en:http://www.cepal.org/es/publicaciones/9773-territorios-en-la-globalizacion-cambio-global-y-estrategias-dedesarrollo 
Bervejillo F. 2010. Puente sobre la Laguna Garzón. Estudio de Impacto Ambiental. CSI Ingenieros S.A. Bojórquez-Tapia L, Díaz-Mondragón S y Ezcurra . 2001 GIS-based approach for participatory decision making and land suitability assessment. International Journal of Geographical InformationScience15(2):129-151. Brenes R. 2006. El Turismo en la Globalización. En: CoRis. Revista de Ciencias Sociales y Humanidades. Vol. 4:21-30. ISSN 1659-2387.

Canter L. 1996. Environmental Impact Assessment. 2nd edn. McGraw-Hill, New York.

Cousillas M. 2016. Modificaciones de la Ley de Presupuesto Nacional a la Legislación Ambiental. En: Revista Tribuna del Abogado. Colegio de Abogados del Uruguay, ำ 196:16-20.

de Álava D. 2007. Incidencia del Proceso de Transformación Antrópico en el Sistema Costero La Paloma Cabo Polonio, Rocha, Uruguay. Tesis Maestría en Ciencias Ambientales. Facultad de Ciencias, UdelaR. Montevideo.

ERC: Equipo Regional Central. Pereyra, Piazzolli, Gómez, Tinaglini, Mogni, Vaselli, Bruno, Franco, Amaro, Ois, Vinay, Pimienta, Araújo, Fabini, Oggero, Escudero, Soto, Vaselli, Van Dam, Larricq, Rodríguez. 2012. Plan Estratégico Desarrollo de la Región Este. Int. Maldonado, Rocha, Treinta y Tres, Lavalleja, Proy. Región E y Prog. Uruguaylntegra.Disponible en:http://www.agev.opp.gub.uy/observatorio_docs/publico/228.pdf

Estévez V. 2012. Calidad y fragilidad visual del paisaje: MCE, fuzzy logic y GIS. Tesis de Maestría. Universidad Complutense de Madrid. Madrid.

EEM - Evaluación de Ecosistemas del Milenio 2003. Informe: Ecosistemas y Bienestar Humano: Marco para la Evaluación. Grupo de Trabajo sobre Marco Conceptual de la Evaluación de Ecosistemas del Milenio.

Fernández R. 2000. Gestión Ambiental de Ciudades, Teoría crítica y aportes metodológicos. Programa de Naciones Unidas para el Medio Ambiente, Red de Formación Ambiental América Latina y Caribe. México. ISBN 968-7913-12-6

Hernández F. 2009. Urbanizaciones privadas en América Latina, los "guetos" del Siglo XXI. El caso del crecimiento de countries y barrios privados en la costa atlántica argentina. Observatorio Geográfico de América Latina. Disponible en: mica/Geografiaurbana/88.pdf

IDR- Intendencia de Rocha, 2010. Decreto Departamental No 17/2005 de 27/12/2005, Dirección de Ordenamiento Territorial. Plan Local de Ordenamiento Territorial Lagunas Costeras (PLOTLC). Rocha.

Leicht E, Rabellino C y Varela A. 2013. Maldonado en perspectiva. Asimetrías y desafíos. En: Capandeguy D. (ed.) Revista de la Facultad de Arquitectura, UdelaR, oㅡ 11:144-155. ISNN 0797-09703/11. Montevideo.

Nario A. 2015. 2008-2015 Siete años de desarrollo y gestión del SNAP. Boletín electrónico SNAP; MVOTMA, mayo 2015. Disponible en: http://www.mvotma.gub.uy/ciudadania/item/10007050-boletin-snap2015.html

Nin M. 2013. Mapeo de servicios ecosistémicos en la cuenca de la Laguna de Rocha como un insumo para la panificación territorial. Tesis Maestría en Ciencias Ambientales, UdelaR. Montevideo.

OMT- Organización Mundial del Turismo 2016. ¿Por qué el turismo? El turismo: un fenómeno económico y social. Disponible en: http://www2.unwto.org/es/content/por-que-el-turismo

Panizza A y García Collazo M. 2014. Experiencias de ordenamiento territorial en Iberoamérica. En: Paruelo J, Jobbágy E, Laterra P, Dieguez H, García Collazo A y Panizza A (eds.) Ordenamiento territorial rural, Conceptos, métodos y experiencias. Ministerio de Agricultura, Ganadería y Pesca de Argentina y Organización de Naciones Unidas-Alimentación y Agricultura (FAO), Facultad Agronomía, Universidad de Buenos Aires y Instituto Nacional de Tecnología :272-300. Buenos Aires.

Poder Ejecutivo. 2009. Decreto $n^{\circ} 221 / 009$. Reglamentación ley sobre ordenamiento territorial y desarrollo sostenible. Urbanización. Montevideo. 
Poder Legislativo. 1994. Ley no 16.466. EIA, Medio ambiente. Declarase de interés general, la protección del mismo, contra cualquier tipo de depredación, destrucción o contaminación. Montevideo.

Poder Legislativo. 2000. Ley no 17.234. Declarase de Interés General la creación y gestión de un Sistema Nacional de Áreas Naturales Protegidas, como instrumento de aplicación de las políticas y planes nacionales de protección ambiental. Montevideo.

Poder Legislativo. 2008. Ley ํㅜ 18.308. Ordenamiento Territorial de Desarrollo Sostenible (LOTDS). Marco Regulador General. Montevideo.

Poder Legislativo. 2009. Ley no 18.567/09 Descentralización política y participación ciudadana. Montevideo.

Poder Legislativo. 2014. Ley no 19.272/14 Ley de Descentralización Departamental, Local y de Participación Ciudadana. Montevideo.

Rodríguez-Gallego L. 2004. Estrategias para el control de la carga de nutrientes del Lago Rodó. Tesis de Maestría en Ciencias Ambientales, UdelaR. Montevideo.

Rodríguez-Gallego L, Nin M, Suárez C, Conde D. 2012a. Propuesta de Plan de Manejo del Paisaje Protegido Laguna de Rocha. Futuro Sustentable S.A. Rocha, Uruguay.

Rodríguez-Gallego L, Achkar M y Conde D. 2012b. Land Suitability Assessment in the Catchment Area of Four Southwestern Atlantic Coastal Lagoons: Multi-criteria and Optimization Modeling. Environmental Management, DOI10.1007/s00267-012-9843-4. ISSN 0364-152X. Springer

Sciandro J. 2013. Foro de discusión: Compatibilidad de las Regulaciones en Áreas Protegidas. Musitelli D. (ed.) PROBIDES Documentos de trabajo $n^{\circ} 51$. Programa de Conservación de la Biodiversidad y Desarrollo Sustentable en los Humedales del Este. Rocha. Disponible en: http://www.probides.org.uy/publica/dt/DT51.

Svampa M. 2001. Los que ganaron. La vida en los countries. Edit. Biblos. ISBN:950-786-306-0. Buenos Aires. 